\title{
Strategies to Translate Information Technology (IT) Terms
}

\author{
Luu Trong Tuan \\ National University of Ho Chi Minh City, Vietnam \\ Email: luutrongtuan@vnn.vn
}

\begin{abstract}
The rendezvous amid translation theories and models is the quest for an approach to translation units, which is especially significant in translating scientific terms outside as well as inside a context. The research seeks to explore two principles of translating terms, "recombination of semantic components" and "functional equivalence", which helps look through terms outside the context and determine if the translation units in translating the IT terms are morphemes, words, or phrases. Based on these term translation principles and Vinay \& Darbelnet's (1977) translation procedures, six procedures of translating terms-direct borrowing, "calque" or loan translation, literal translation, transposition, modulation, and adaptation-are developed. Besides, Coordinate Translation Model with three axes: $X$ axis-translation unit axis, $Y$ axis-concept equivalent axis, and $\mathrm{Z}$ axis-language task schema axis is proposed to locate appropriate translation units for translating IT terms inside the context.
\end{abstract}

Index Terms-scientific term, IT term, recombination of semantic components, functional equivalence, translation unit, Coordinate Translation Model

\section{INTRODUCTION}

Scientific language is characterized by specific lexical system. Besides purely technical words, semi-technical words such as hypothesis, experiment, analysis, and description are shared by a variety of disciplines. Neologisms incessantly emerge and penetrate scientific language.

The standardization in translating scientific terms are essential for scientific research as well as academic exchange. Scientific translation differs from the other types of translation primarily in terms of terms in scientific texts (Newmark, 1995, p. 151). While literary translation turns to the authors' aesthetic intention, scientific translation centers on the accuracy of scientific terms. Translating terms can be a challenge for translators once even certain bilingual dictionaries of a science fail to distinguish academic meaning of a term from its common meaning. For instance, in the bilingual IT dictionary by Quang et al. (2009), the terms "blog" và "diary" are translated as "nhật ký" ("a daily record") in Vietnamese language.

A questionnaire survey conducted among the IT students at University of Natural Sciences, Ho Chi Minh City (UNSHCMC) revealed learners' incapacity to explore the semantics of words, especially scientific terms. The data from the survey demonstrated that $76.29 \%$ of the students resorted to English-Vietnamese dictionaries upon the encounter with new IT terms, and a high rate of the students $(79.38 \%)$ who did not developed the habit of visiting monolingual IT dictionaries. They, in addition, were not accustomed to strategies to analyze roots of words $(84.54 \%)$ or infer their meanings from their contexts $(82.47 \%)$.

From the significance of accurately translating terms in scientific texts in general and in IT texts in particular, the article seeks to explore principles as well as procedures of term translation, contributing to the accuracy of scientific translation.

\section{PRINCIPLES OF TRANSLATING TERMS}

Term translation can be guided by the two subsequent principles. 


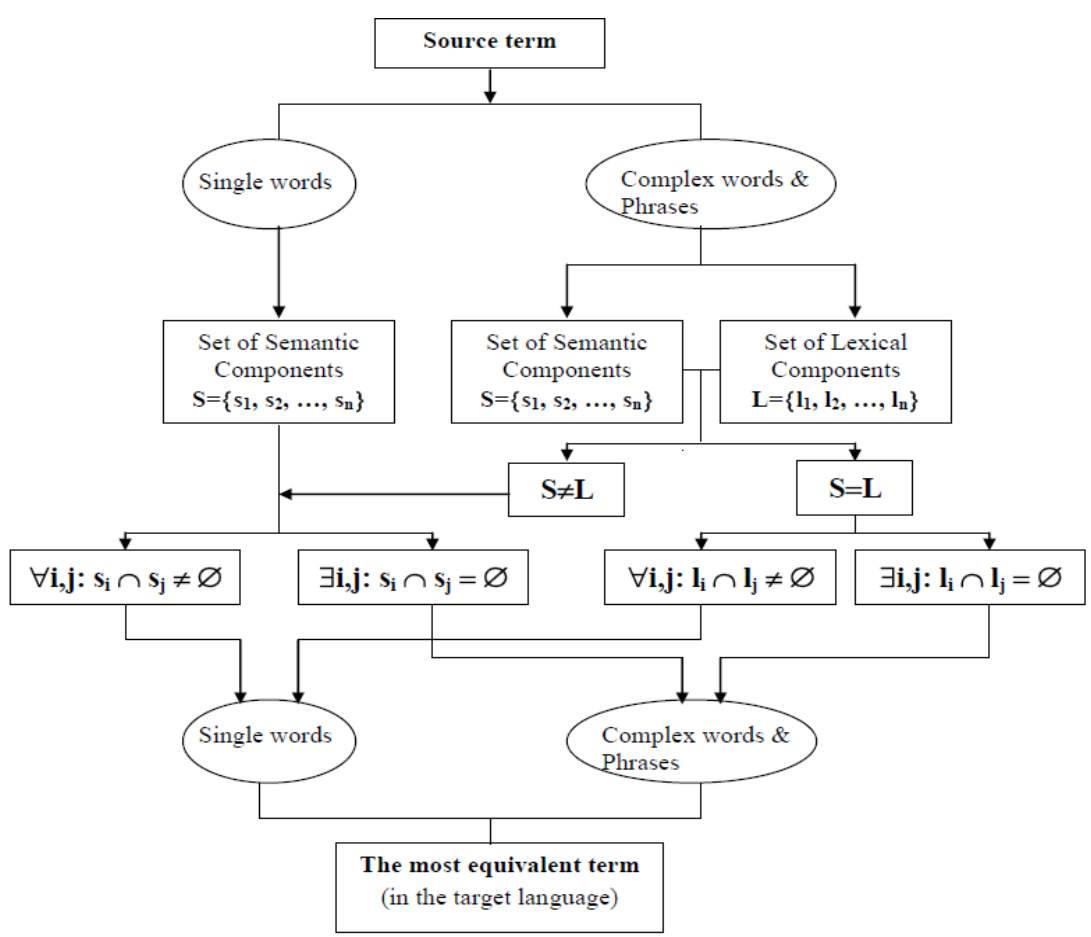

Figure 1. Recombination of semantic components in term translation

\section{A. Recombination of Semantic Components}

Even though English terms and Vietnamese terms represent three formations: single word, complex word, and phrase, translating English terms into Vietnamese language is not always a bijective mapping in formation, i.e. English single words, complex words, and phrases are translated as Vietnamese single words, complex words, and phrases respectively, but may display the recombination of the semantic components of the terms in the target language. If the semantic components in the target language are tightly compacted, the translated terms will be single words, and if the semantic components in the target language are loosely compacted, the translated terms will be complex words or phrases. Principle of recombinating semantic components can be summarized in the Figure 1.

Figure 1 shows that if a term is a single word, the translator will analyze its set of semantic components $\mathbf{S}=\left\{\mathbf{s}_{\mathbf{1}}, \mathbf{s}_{\mathbf{2}}, \ldots\right.$, $\left.\mathbf{s}_{\mathbf{n}}\right\}$ (S=semantic component) (the set of semantic components is explored through its definition). In case its semantic components are tightly compacted, i.e. subsets of every semantic component are joint, or their intersection is not the empty set $\left(\forall \mathbf{i}, \mathbf{j}: \mathbf{s}_{\mathbf{i}} \cap \mathbf{s}_{\mathbf{j}} \neq \varnothing\right)$, term translation in the target language will be a single word as "file" is translated as "tệp" in Vietnamese language.

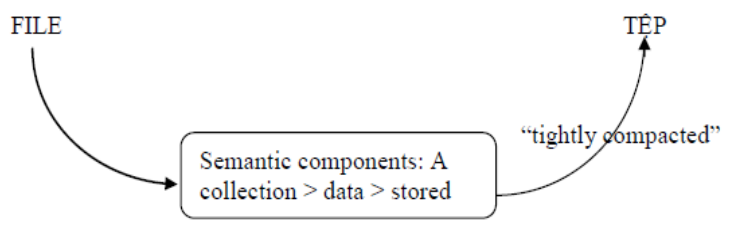

Nonetheless, if the semantic components of a single word are not tightly joint, i.e. there exist at least two disjoint subsets of semantic components, or their intersection is the empty set $\left(\exists \mathbf{i}, \mathbf{j}: \mathbf{s}_{\mathbf{i}} \cap \mathbf{s}_{\mathbf{j}}=\varnothing\right)$, term translation in the target language will be a complex word or phrase as "computer" is translated as "máy tính" and "serial" is translated as "truyền tuần tự" in Vietnamese language. 


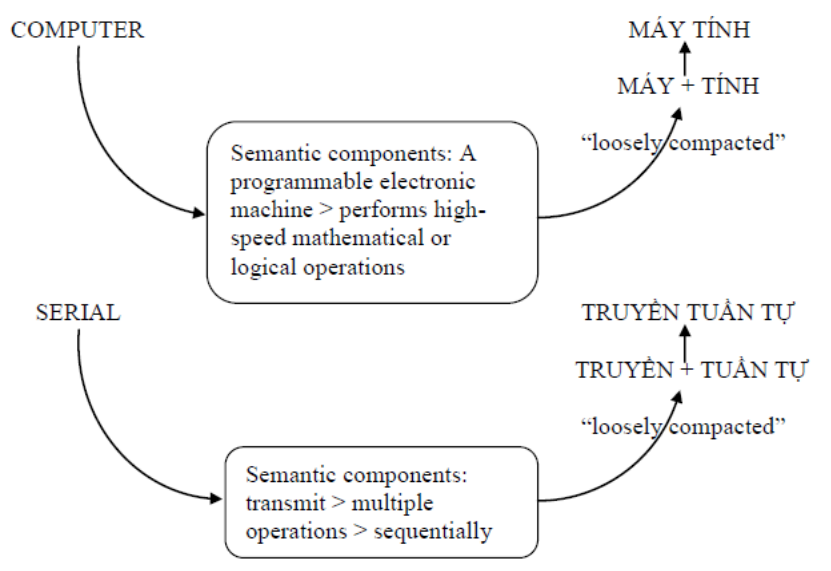

In case the term is a complex word or phrase, the translator has to analyze its set of semantic components $\mathbf{S}=\left\{\mathbf{s}_{\mathbf{1}}\right.$, $\left.\mathbf{s}_{\mathbf{2}}, \ldots, \mathbf{s}_{\mathbf{n}}\right\}$ (S=semantic component) and its set of lexical components $\left(\mathbf{L}=\left\{\mathbf{l}_{\mathbf{1}}, \mathbf{l}_{\mathbf{2}}, \ldots, \mathbf{l}_{\mathbf{n}}\right\}\right)$ ( $\mathrm{L}=$ lexical component). If its set of lexcical components does not reflect its set of semantic components $(\mathbf{S} \neq \mathbf{C})$, then its set of semantic components should be analyzed, like the case of the term as a single word; for instance, "homepage" is translated as "trang chü" in Vietnamese language.

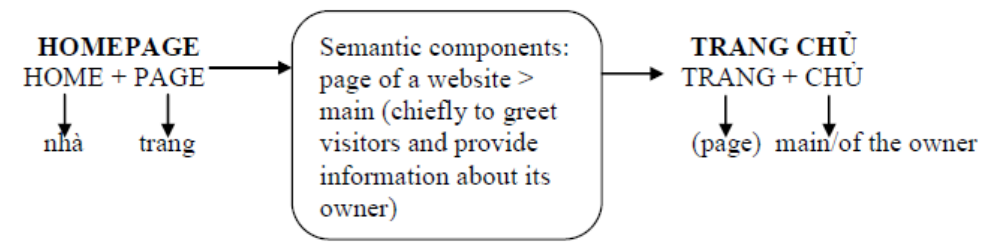

Nevertheless, if the lexical components of a complex word or phrase are not tightly joint, i.e. there exist at least two disjoint subsets of lexical components, or their intersection is the empty set $\left(\exists \mathbf{i}, \mathbf{j}: \mathbf{l}_{\mathbf{i}} \cap \mathbf{l}_{\mathbf{j}}=\varnothing\right)$, term translation in the target language will be a complex word or phrase as "random access memory" is translated as "bộ nhớ truy cập ngẫu nhiên" in Vietnamese language, a recombination of disjoint translated lexical components.

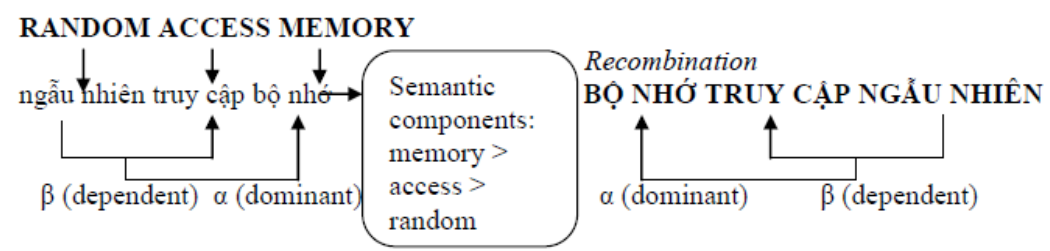

\section{B. Functional Equivalence Principle}

When a term is translated, the equivalence between the term in the source language and its translation in the target language seeks to be attained. However, this does not imply a word-for-word translation, but the content of the term should be transferred so as to achieve functional equivalence. According to Arntz \& Picht (1991, p. 160), there are four degrees of functional equivalence:

1) Complete conceptual equivalence

This degree of functional equivalence can be found in the case of "artificial intelligence" to be translated as "trí tuệ nhân tạo" (trí tuệ: intelligence; nhân tạo: artificial), and "polymorphism" (poly-: multiple; -morphism: form) to be translated as "đa hình" (đa: multiple; hình: form).

2) Partial equivalence, overlapping

This degree of functional equivalence can be found in translating the term "online". The intersection between the term "online" and its translated term "trực tuyến" is the component "line" ("tuyến" implying "line"), whereas the other component of the term "on" is not equivalent to the component "trực" (straight) of the translated term.

Similarly, "homepage" is translated as "trang chü" in Vietnamese language; nonetheless, their mere intersection is "page" ("trang" meaning "page"), and the other component of the term "home" and that of its translated term "chü" (owner) are unequivalent, so the term and its translated term are partially equivalent.

The interface between the term "webhard" and its translated term "ổ đĩa cứng trực tuyến" - the component "hard" ("cứng" meaning "hard") - is even narrower. In the translated term, the component "trực tuyến" (online) is unequivalent to the component "web" of the source term, and the component "ổ đĩa" (disk) is added. 
3) Inclusion, a term merges into another

The term "computer" is translated as "máy tính" in Vietnamese language, which means "a device that calculates or computes", so its translation "máy tính" is a hypernym embracing the hyponyms "computer" and "calculator".

On the contrary, the hypernym "ring" in IT terminology does not have the equivalent hypernym in Vietnamese language. Thus, it tends to be translated through the hyponyms of the term "ring" as:

+ "vành" (a circular band): $\quad$ ring function $\rightarrow$ hàm vành

+ "vòng" (a circular line): $\quad$ ring counter $\rightarrow$ bộ đếm vòng

4) No conceptual equivalence

The term "debug" is literally translated as "khử côn trùng" (remove insects); however, its common translation "gỡ rối" (shoot troubles) is entirely unequivalent to the term.

\section{TERM TRANSLATION PROCEDURES}

The two term translation principles "recombination of semantic components" and "functional equivalence" can be developed into six term translation procedures, corresponding to six out of Vinay \& Darbelnet's (1977) translation procedures, which are direct borrowing, "calque" or loan translation, literal translation, transposition, modulation, and adaptation.

\section{A. Direct Borrowing}

Borrowing is categorized into direct and indirect borrowing. Direct borrowing consists of native words in donor language, whereas indirect borrowing comprises words borrowed through donor language. According to Fromkin (2000 p. 512), native words are those which can be etymologically traced back to the most primitive phase of that language. A number of English IT terms such as bus, avatar, outlook express have penetrated IT jargon in Vietnam. Even though direct borrowing is becoming the increasingly common terminology translation procedure, this should be the last resort as suggested by Ohly (1987). Thus, "e-mail" and "download" should be translated as "thư điện tử" and "tải xuống" respectively, rather than being retained in the target language.

\section{B. Calque/Loan Translation}

In calque or loan translation procedure, the lexical components of the source term is translated, then arranged in the target language in an order similar or nearly similar to that of the lexical components of the source term:

analogue + signal

tương tự tín hiệu = tín hiệu tương tự

\section{Literal Translation}

Literal translation tends to occur when the set of semantic components and the set of lexical components coincide. This especially takes place when the source term consists of Latin lexical components queuing in an order similar to that of the lexical components of the Vietnamese term:

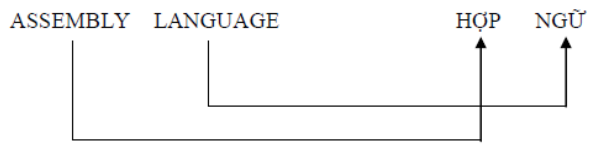

The above instance illustrates the coincidence of loan translation and literal translation. However, literal translation tends to entail the semantic relationship among the components, whereas loan translation involves the syntax of the components. For instance,

Loan translation:

data + structure

dữ liệu cấu trúc $=$ cấu trúc dữ liệu

Literal translation:

loop + structure

vòng cấu trúc $=$ cấu trúc vòng lặp

Literal translation elucidates the semantic relationship between the two components "loop" and "structure", so "loop structure" is translated as "cấu trúc vòng lặp" (instead of "cấu trúc vòng") highlighting the iteration (which "lặp" means) of this structure.

\section{Transposition}

Transposition entails the grammatical changes but no semantic changes. The following examples denote the change in syntax from the source term to its translation:

Ring main (ring: dependent—main: dominant) $\rightarrow$ mạch vành chính (mạch vành (= ring): dominant—chính $(=$ main): dependent)

\section{E. Modulation}


Van Hoof describes modulation as a type of transposition at the global level, applying to categories of thought, not grammatical categories (1989, p. 126).

In the IT English, the adjective "online" composed of the preposition "on" and the noun "line" is defined as "connected to a computer or the Internet". However, it is not translated as "nối mạng", the equivalent of this definition, but translated as "trực tuyến" composed of the verb "trực" (i.e. move straight) and the noun "tuyến" (i.e. line). "Trực tuyến", which implies "move straight through the line to" and so, implies "connected", is a transposition of thought or modulation.

Likewise, the adjective "offline" composed of the preposition "off" and the noun "line" is defined as "disconnected from a computer system or the Internet". It, nonetheless, is not translated as "ngắt mạng", the equivalent of the aforementioned definition, but translated as "ngoại tuyến" composed of the preposition "ngoại" (i.e. outside) and the noun "tuyến" (i.e. line). "Ngoại tuyến", which implies "outside the line" and so, implies "not connected", is another transposition of thought or modulation.

\section{F. Adaptation}

Adaptation is the search for the term's equivalent in the target language based on its set of semantic component as a whole, rather than translating each semantic or lexical component of the term.

The term "algorithm" originates from the name of the mathematician Al-Khawarimiz, so its translation, "thuật toán/giải thuật", is predicated on its definition: "a set of precise rules or instructions for solving a problem".

Analogously, the set of semantic components of "debug" $S=\{$ de- (i.e. remove), bug (i.e. insects) $\}$ does not help find the equivalent of this term in the target language, so its definition "to search for and eliminate malfunctioning elements or errors in" is relied on to produce its translation "gỡ rối" with "gỡ" implying "emiminate" and "rối" referring to malfunctioning elements".

\section{TRAnSlating TERMS IN THE CONTEXT}

\section{A. Coordinate Translation Model}

The rendezvous among translation theories and models is the quest for the equivalents in the target language, the first step of which is to identify the translation units defined by Zhu (1999) as:

The smallest segment[s] of an SL text which can be translated as an independent and integrated meaning entity in relation to other segments of the text. Its formal realization, if viewed in isolation, is analyzable on levels ranging from the morpheme to the sentence; its textual potential, however, is based on the completeness of its information structure, and is normally realized when it performs textual functions in the SL text. These textual functions are to be matched in the construction of a TL text.

The journey to translation units is portrayed by Walter Benjamin as reaching the tryst where the translation and the source text echo the same pitch (see Cao, 2005).

Thus, a translation model should have two axes: translation unit axis and concept equivalent axis. The translator will move along translation unit axis to locate the translation unit, then project to concept equivalent axis to see if the equivalent exists in the target language. Moreover, language task schema axis which scans along the source text is needed. Language task schema, one of the three basic loci of control in the Inhibitory Control (IC)) model of Green (1998a, b), is established by the translator to translate between languages.

Therefore, Coordinate Translation Model is proposed to be built upon three axes: X axis - translation unit axis, Y axis - concept equivalent axis, and $\mathrm{Z}$ axis - language task schema axis as illustrated in Figure 2 (In Euclidean geometry, a translation is moving every point a constant distance in a specified direction).

In order to locate the translation unit $\mathrm{x}_{\mathrm{i}}$, the translator tends to move from the start of a sentence searching phrases. For instance, as the translator reaches a noun phrase and find it a term, she or he decomposes it into words and consider words as translation units $\left(\mathrm{x}_{\mathrm{i}}=\right.$ word $)$. However, in case the translator projects to the concept equivalent axis, i.e. project to the target language, and find no $\mathrm{T}_{\mathrm{i}}\left(\mathrm{x}_{\mathrm{i}}, \mathrm{y}_{\mathrm{i}},-\mathrm{z}_{\mathrm{i}}\right)$ (T=target) $\left(-\mathrm{z}_{\mathrm{i}}\right.$ in the target language is symmetrical to $\mathrm{z}_{\mathrm{i}}$ in the source language) equivalent to $S_{i}\left(x_{i}, y_{i}, z_{i}\right)(S=$ source $)$. Then, the translator will move from $S_{i}$ to $S_{i+1}\left(x_{i+1}, y_{i+1}, z_{i}\right)\left(S_{i+1}\right.$ has the coordinate $z_{i}$ since it remains on the same language task schema plane as $S_{i}$ ), i.e. move from $x_{i}\left(\right.$ word) $\rightarrow x_{i+1}($ phrase), and in this case, encounter its equivalent $\mathrm{T}_{\mathrm{i}+1}\left(\mathrm{x}_{\mathrm{i}+1}, \mathrm{y}_{\mathrm{i}+1},-\mathrm{z}_{\mathrm{i}}\right)$ in the target language. For instance, at the point $\mathrm{S}_{\mathrm{i}}$ of the source text, the translator comes across the noun phrase "last mile". If the translator chooses word as the translation unit: $\mathrm{x}_{\mathrm{i}}=$ word $=\{[$ last $][$ mile $]\}$, then she or he is unable to find the equivalent $\mathrm{T}_{\mathrm{i}}\left(\mathrm{x}_{\mathrm{i}}, \mathrm{y}_{\mathrm{i}},-\mathrm{z}_{\mathrm{i}}\right)$ in the IT target jargon; nonetheless, if the translator moves from $\mathrm{x}_{\mathrm{i}} \rightarrow \mathrm{x}_{\mathrm{i}+1}=$ word $\rightarrow$ phrase, then she or he will find the equivalent in the target language, which involves the relationship between [last] and [mile] $=[$ last $] \mathbf{R}$ [mile] $=\{$ The connection between the customer and the telephone company, cable company or ISP \}. 


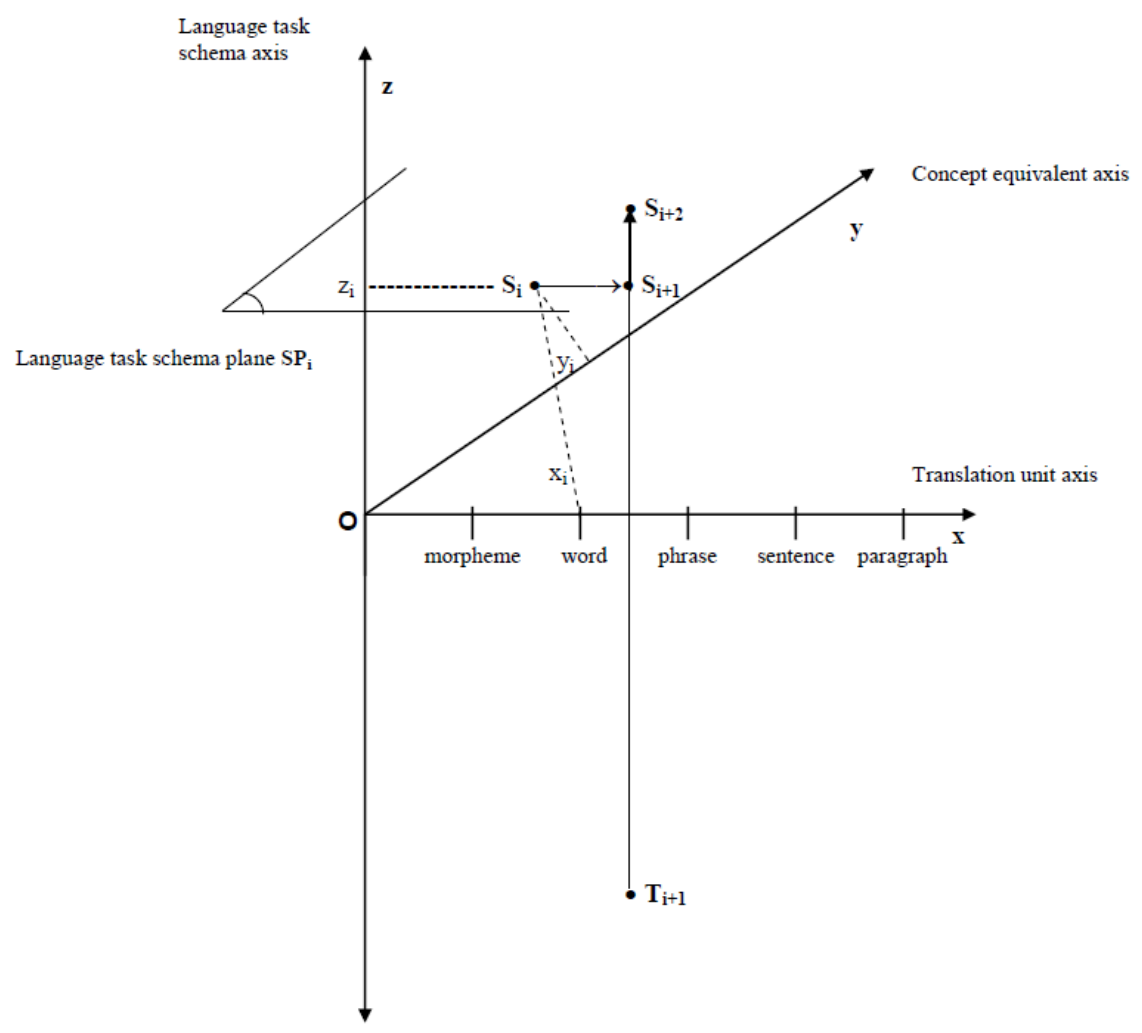

Figure 2. Coordinate translation model

\section{B. Translating Terms in the Context}

As an unfamiliar term manifests itself in a context, if it is a single word or derivative, its set of semantic components can be likely identified; however, if it is a phrase, it must be distinguished from an unidiomatic phrase by analyzing the interactions between the term and the rest of the sentence, the other sentences in the theme-rheme progession, the text type and style, and even the text title. The analysis of these interactions will help determine whether the phrase in the context is a term or an unidiomatic phrase, i.e. the translation unit(s) is (are) a phrase or words. Consider the following text:

(1) Visual Basic loop structures allow you to run one or more lines of code repetitively. (2) You can repeat the statements in a loop structure until a condition is True, until a condition is False, a specified number of times, or once for each element in a collection.

(3) The following illustration shows a loop structure that runs a set of statements until a condition becomes true.

\section{Running a set of statements until a condition becomes true}

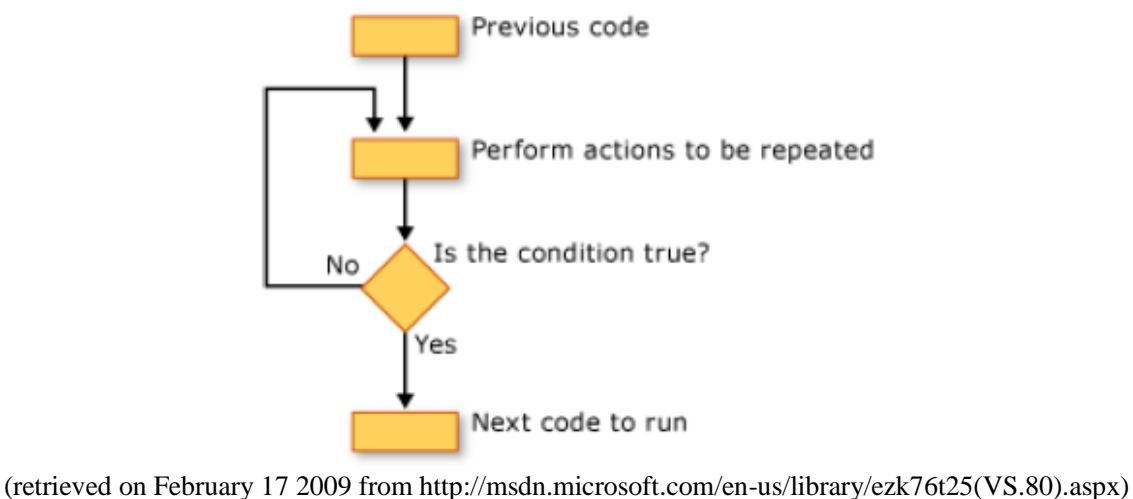

Facing the phrase "loop structures" in the above text, the translator needs to determine if the translation unit(s) is (are) the whole phrase "loop structures" or words "loop" [shape > circular or curved over on itself] and "structures" [parts > arranged or put together to form a whole body]. The semantic interaction between the phrase "loop structures" and the intra-sentential/inter-sentential components "repetitively" in the first sentence and "repeat" in the second sentence 
shows that the component "loop" does not merely literally refer to the circular shape in the arrangement of the statements, but further highlight the iteration in these structures. Thus, there is a transition from $\mathrm{x}_{\mathrm{i}} \rightarrow \mathrm{x}_{\mathrm{i}+1}=$ word $\rightarrow$ phrase, and the term "loop structures" is translated as "cấu trúc vòng lặp" (structure + loop depicting the iterativeness), not "cấu trúc vòng" (structure + loop-shaped) in Vietnamese language.

\section{CONCLUDing REMARKS}

Even though terms take up a modest ratio in the content of the scientific text, $5-10 \%$ as Newmark (1995, p. 151) states, they are building blocks contributing to scientific style. Achieving the accuracy in translating terms in the scientific texts helps project scientific style in the source text to the target language. This article explores two principles of translating IT terms: recombination of semantic components and functional equivalence. Functional equivalence principle involves complete conceptual equivalence, partial equivalence, inclusion, and no conceptual equivalence. From these two principles, six term translation procedures, corresponding to six of Vinay \& Darbelnet's (1977) translation procedures, embracing direct borrowing, "calque" or loan translation, literal translation, transposition, modulation, and adaptation, are discussed. Among these term translation procedures, direct borrowing, "calque" or loan translation, and literal translation are source-oriented translation procedures, whereas transposition, modulation, and adaptation are source-independent or target-oriented translation procedures. The article also proposes Coordinate Translation Model built upon three axes: $\mathrm{X}$ axis - translation unit axis, $\mathrm{Y}$ axis - concept equivalent axis, and $\mathrm{Z}$ axis language task schema axis, which helps the translator locate the appropriate translation units and project to concept equivalent axis to reach the equivalents in the target language.

\section{REFERENCES}

[1] Arntz, R, \& Picht, H. (1991). Einführung in die Terminologiearbeit. Hildesheim: Olms.

[2] Cao, V.D. (2005). Suy nghĩ về dịch thuật và ngôn ngữ văn chương (Thoughts on Translation and Literary Language). Retrieved on July 92008 from http://vietnamnet.vn/vanhoa/chuyende/2005/12/526939/

[3] Fromkin, V. (Ed.) (2000). Linguistics: An Introduction to Linguistic Theory. Oxford: Blackwell Publishers.

[4] Green, D.W. (1998a). Mental control of the bilingual lexico-semantic system. Bilingualism, No. 1, pp. 67-81.

[5] Green, D.W. (1998b). Schemas, tags and inhibition. Reply to commentators. Bilingualism, No. 1, pp. 100-4.

[6] Newmark, P. (1995). A Textbook of Translation. London: Prentice Hall Europe.

[7] Ohly, R. (1987). Primary Technical Dictionary. Institute of Production Innovation, Dar-es-saalam and Deustche Gesellschaft fu r Technische Zusammernarbeit, Eschborn.

[8] Quang, H., Ta, Q.H., Nguyen, P.K., \& Do, D.V. (2009). Từ điển Bách khoa Công nghệ Thông tin \& Kỹ thuật Máy tính AnhViệt (English-Vietnamese Information Technology \& Computer Technology Dictionary). Ho Chi Minh City: Hong Duc Publishing House.

[9] Van Hoof, H. (1989). Traduire l'Anglais. Paris \& Louvain-la-neuve: Duculot.

[10] Vinay, J.P., \& Darbelnet, J. (1977). Stylistique Comparée du Français et de L’Anglais. Paris: Didier.

[11] Zhu, C. (1999). Ut once more: The sentence as the key functional unit of translation. Meta: Translators' Journal, Vol. 44, No. 3, p. 429-447.

Luu Trong Tuan is currently an EFL teacher at National University of Ho Chi Minh City. He received his M.TESOL from Victoria University, Australia in 2004. Besides his focus on TESOL, his recent publications such as Language Transfer is Cultural Transfer between Communities, Social Sciences Review, No. 11, 2004, pp 60-63; and Principles for Scientific Translation, Social Sciences Review, No. 8, 2004, pp 63-67 show his profound interest in language contact and translation areas. 